\title{
Endoscopic Treatment of Upper Gastrointestinal Bleeding Using Haemoseal Spray: A Retrospective, Observational Study from a Tertiary Center in North India
}

\author{
Rinkesh Kumar Bansal ${ }^{1}$ \\ Avnish Kumar Seth ${ }^{1}$
}

Address for correspondence Avnish Kumar Seth, MD, DM, Department of Gastroenterology and Hepatobiliary Sciences, Fortis Organ Retrieval and Transplant (FORT), Gurugram, Haryana 122002, India (e-mail: akseth2003@yahoo.com).

\begin{abstract}
Introduction United States Food and Drug Administration recently approved use of Hemospray for the management of gastrointestinal (GI) Bleeding. We report our experience with Haemoseal Spray (HS, Shaili Endoscopy) for the treatment of upper GI bleeding (UGIB).

Methods Records of patients who received HS for UGIB from January 2013 to June 2018 were studied retrospectively. Patients with UGIB from focal lesions refractory to conventional endotherapy or those with diffuse/multiple lesions not amenable to conventional endotherapy received $5 \mathrm{cc}$ HS spray. Primary end-point studied was clinical success, defined as control of bleeding over 24 hours. Secondary end-points evaluated included recurrence of bleeding within 7 days, in-hospital mortality, and complications secondary to HS.

Results Thirty-eight patients were treated with HS. The median age was 57 (range: 5-87) years with 27 males and 11 females. In 24 patients, HS was used as monotherapy, while it was combined with Injection/Clip/Argon Plasma Coagulation in 14. Etiology of bleeding was ulcers or erosions in 22, malignancy in 10, portal hypertensive gastropathy/gastric antral vascular ectasia in 4 , and radiation gastropathy in 2 . Clinical success was achieved in 32/38 (84\%). All six nonresponders had coagulopathy related to chemotherapy/bone marrow transplant. Recurrent bleeding within 7 days was observed in four patients (gastric malignancy 2, radiation gastropathy 2 ). In-hospital mortality was seen in $8 / 38$ (21\%) of which $2(4.8 \%)$ were directly related to ongoing $\mathrm{Gl}$ bleeding. There was no procedure-related complication.

\section{Keywords}

- endoscopic treatment

- Haemoseal Spray

- upper GI bleeding

Conclusion HS is an effective and safe tool in the endoscopic management of UGIB due to diffuse or multiple focal lesions or focal lesions refractory to conventional endotherapy.
\end{abstract}

DOI https://doi.org/

$10.1055 / \mathrm{s}-0040-1722387$

ISSN 0976-5042. (c) 2020. Society of Gastrointestinal Endoscopy of India.

This is an open access article published by Thieme under the terms of the Creative Commons Attribution-NonDerivative-NonCommercial-License, permitting copying and reproduction so long as the original work is given appropriate credit. Contents may not be used for commercial purposes, or adapted, remixed, transformed or built upon. (https://creativecommons.org/licenses/by-nc-nd/4.0/).

Thieme Medical and Scientific Publishers Pvt. Ltd. A-12, 2nd Floor, Sector 2, Noida-201301 UP, India 


\section{Introduction}

Upper gastrointestinal bleeding (UGIB) is commonly associated with morbidity and mortality with a worldwide annual incidence of $\sim 40$ to 150 per 100,000 and mortality rate of $10 \%{ }^{1}$ Common causes of UGIB include peptic ulcers, erosive gastritis, portal hypertension, malignancies, vascular malformations, and Mallory-Weiss syndrome. Endoscopic management of UGIB includes conventional methods like injection, mechanical and thermal modalities. European Society of Gastroenterology guidelines recommend a combination of two modalities for the management of peptic ulcer bleeding. With a combination of modalities, hemostasis can be achieved in 85 to $95 \%$ patients but rebleeding occurs in 5 to $10 \%{ }^{2}$ Endoscopic therapy of difficult, diffuse, multiple or large lesions, however, remains a challenge. We report our single-center experience with Haemoseal Spray (HS) in patients with UGIB over a 5-year period.

\section{Patients and Methods}

Records of patients who received HS for endoscopic hemostasis for UGIB at our tertiary center in North India from January 2013 to June 2018 were studied retrospectively. Patients with UGIB not controlled with conventional therapy and patients not amenable to conventional therapy due to diffuse/multiple lesions were included. Conventional therapy was defined as use of intravenous proton pump inhibitor, and endotherapy with the use of $1 ; 10,000$ epinephrine or saline injection, application of clip, or Argon Plasma Coagulation (APC) singly or in combination. Patients with known allergy to egg (as collagen powder used in the study was prepared from egg cell membrane) or multiple allergies were excluded from this study. This study was approved by the local institutional review board.

Primary end-point was clinical success, defined as control of bleeding over 24 hours. Secondary end-points studied were recurrent bleeding within 7 days, in-hospital mortality, and complications secondary to HS.

The criteria for recurrent bleeding included recurrence of hematemesis or melena, development of hemodynamic instability, drop in hemoglobin by $2 \mathrm{~g} / \mathrm{dL}$ or more, transfusion requirement of 4 or more units, or presence of bleeding from the treated site at follow-up endoscopy.

UGI endoscopy was performed with Olympus gastroduodenoscope (GIFH180) within 12 hours of presentation. Nasogastric tube insertion with gastric lavage and administration of $20 \mathrm{mg}$ of Metoclopramide or $25 \mathrm{mg}$ of levosulpiride were routinely performed. All procedures were performed under sedation by using midazolam/fentanyl/propofol administered by anesthesiologist. During endoscopy, all attempts were made to identify the exact source of bleeding with flushing and removal of clots where feasible.

In patients with focal lesions, HS was used as salvage therapy when bleeding could not be controlled with conventional methods outlined above. In patients with multiple or diffuse lesions, HS was used as primary treatment modality. The HS kit consisted of an air pump, Haemoseal probe, a 7.5 Fr spray catheter, $230 \mathrm{~cm}$ in length (Shaili Endoscopy, India), and a preloaded collagen cartridge containing $5 \mathrm{~g}$ of powder (-Fig. 1). The spray catheter was passed through the working channel of the endoscope. Collagen powder was applied in short bursts through the spray catheter with an air pump. To prevent clogging of the HS catheter, care was taken to first dry the channel of the endoscope by flushing with $100 \mathrm{cc}$ of air and avoiding the contact of catheter tip with the mucosa.

\section{Result}

Thirty-eight patients received HS in this study. The median age was 57 (range: 5-87) years with 27 males and 11 females. In 24 patients, HS was used as monotherapy (patients not amenable to conventional therapy due to diffuse/multiple lesions), while it was combined with APC/injection/clip application in 14 (patients not controlled with conventional therapy, that is, salvage therapy) ( $\boldsymbol{- F i g . ~ 2 A}$ and B). All patients were kept nil by mouth following the procedure and received intravenous pantoprazole at a dose of $8 \mathrm{mg}$ per hour for 24 hours.

Eighteen patients (47.4\%) had underlying gastrointestinal malignancy, 8 patients $(21 \%)$ had history of coronary artery disease, 6 patients (15.8\%) had history of chronic liver diseases, 3 patients (7.9\%) had chronic kidney disease, and 2 patients (5.2\%) had cerebrovascular disease. Seven patients (18.4\%) had history of antiplatelets drug ingestion either aspirin $75 \mathrm{mg}$ and or clopidogrel $75 \mathrm{mg}$, two (5.2\%) had history of ingestion of oral anticoagulant warfarin $2 \mathrm{mg}$, and $4 \mathrm{mg}$ daily and in two patients (5.2\%) there was history of nonsteroidal anti-inflammatory drug intake ( - Table $\mathbf{1}$ ).

Indications were ulcers or erosions in 22 , malignancy in 10, portal hypertensive gastropathy/gastric antral vascular ectasia in 4 , and radiation gastropathy in 2 . There were 32 (84\%) inpatients, 5 of whom were admitted to intensive care unit. Among ulcers, 11 patients had esophageal ulcers,

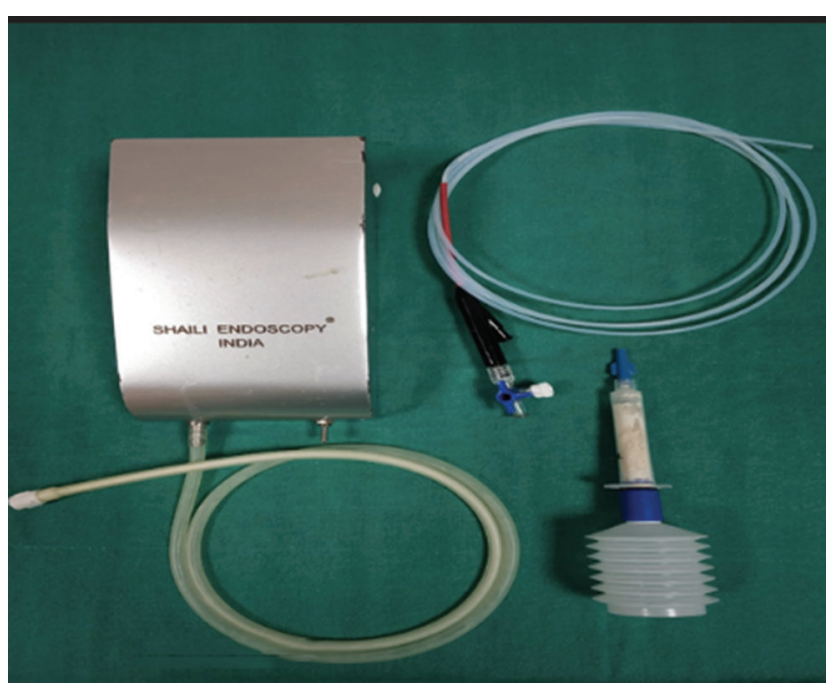

Fig. 1 Components of Haemoseal Spray (pump with connecting tubes, Haemoseal probe, Fibro protein in preloaded syringe). 
Table 1 Associated comorbidities and use of drugs in patients with upper gastrointestinal bleeding

\begin{tabular}{|l|l|}
\hline Co-morbidities and drug use & $n(\%)$ \\
\hline Coronary artery disease & $8(21)$ \\
\hline Chronic liver disease & $6(15.8)$ \\
\hline Chronic kidney disease & $3(7.9)$ \\
\hline Cerebrovascular disease & $2(5.2)$ \\
\hline Antiplatelet drugs & $7(18.4)$ \\
\hline Oral anticoagulants & $2(5.2)$ \\
\hline Nonsteroidal anti-inflammatory drugs & $2(5.2)$ \\
\hline
\end{tabular}

Table 2 Causes of upper gastrointestinal bleeding

\begin{tabular}{|l|l|}
\hline Etiology of bleeding & No. of patients (\%) \\
\hline Ulcers & $22(57.9)$ \\
\hline Esophagus & $5(13.2)$ \\
\hline $\begin{array}{l}\text { Gastroesophageal reflux } \\
\text { disease }\end{array}$ & $3(7.9)$ \\
\hline Infective ulcers & $1(2.6)$ \\
\hline $\begin{array}{l}\text { Post-chemotherapy ulcers } \\
\text { Cameron }\end{array}$ & $1(2.6)$ \\
\hline Mallory-Weiss syndrome & $1(2.6)$ \\
\hline Stomach & $5(13.2)$ \\
\hline Peptic ulcers & $2(5.3)$ \\
\hline Anastomotic ulcers & $1(2.6)$ \\
\hline Corrosive poisoning & $3(7.9)$ \\
\hline Duodenal & $10(26.3)$ \\
\hline Peptic ulcers & $4(10.5)$ \\
\hline Malignancy & $2(5.3)$ \\
\hline Gastric carcinoma & $4(10.5)$ \\
\hline Gastric lymphoma & $2(5.3)$ \\
\hline Local duodenal infiltration & $1(2.6)$ \\
\hline Carcinoma gall bladder & $1(2.6)$ \\
\hline Hepatocellular carcinoma & $4(10.5)$ \\
\hline Periampullary & $3(7.9)$ \\
\hline $\begin{array}{l}\text { Portal hypertensive } \\
\text { gastropathy/GAVE }\end{array}$ & $1(2.6)$ \\
\hline GAVE & $2(5.3)$ \\
\hline PHG & Radiation gastropathy \\
\hline
\end{tabular}

Abbreviations: GAVE, gastric antral vascular ectasia; PHG, portal hypertensive gastropathy.

8 patients had gastric ulcers, and 3 patients had duodenal ulcers (-Table 2).

Clinical success was achieved in 32/38 (84\%). All six nonresponders had coagulopathy related to chemotherapy/bone marrow transplant. Follow-up endoscopy was done within 24 hours in 4 patients and after 24 hours in 2 patients.

Follow-up UGI endoscopy was not routinely performed. Repeat UGI endoscopy for recurrent bleeding within 7 days was observed in 4 patients (gastric malignancy 2, radiation gastropathy 2 ). In-hospital mortality was seen in 8/38 (21\%) patients, of whom $2 / 38$ (4.8\%) were related to active ongoing GI bleeding (-Table 3). There was no therapy-related complication
Table 3 Causes of mortality

\begin{tabular}{|l|l|}
\hline Cause of mortality & No. of patients (\%) \\
\hline Sepsis & $2(5.2)$ \\
\hline Bleeding related & $2(5.2)$ \\
\hline Acute coronary syndrome & $1(2.6)$ \\
\hline Cardiac arrhythmia & $1(2.6)$ \\
\hline Aspiration & $1(2.6)$ \\
\hline End-stage liver disease & $1(2.6)$ \\
\hline
\end{tabular}

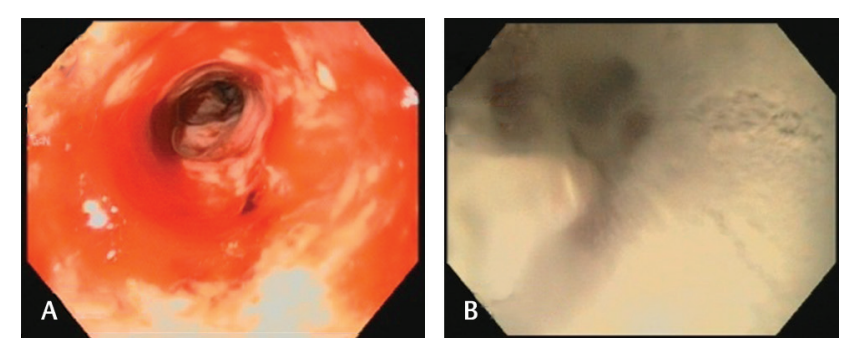

Fig. 2 (A) Endoscopic image showing diffuse upper gastrointestinal bleeding. (B) Endoscopic image of hemostasis after Haemoseal Spray in diffuse upper gastrointestinal bleeding.

\section{Discussion}

United States Food and Drug Administration recently approved the use of Hemospray for the management of GI bleeding. Various hemostatic powders are available for use during endoscopy, that is, Ankaferd Blood Stopper, Hemospray (TC-325), Endoclot Polysaccharide Hemostatic System, and HS. ${ }^{3-6}$ Hemospray (Cook Medical, Winston-Salem, North Carolina, United States) consists of an inorganic powder that becomes cohesive and adhesive on coming in contact with moisture, thus forming a stable mechanical barrier and sealing the site of bleeding. Due to its composition, it is neither absorbed nor metabolized within the mucosa, hence minimizing the risk of systemic toxicity. ${ }^{4} \mathrm{HS}$ consists of collagen that is the major protein of the extracellular matrix. It activates intrinsic coagulation pathway as well as platelet activation. Collagen acts as a scaffold in tissues because of its stiff, triple-stranded helical structure. ${ }^{7}$ Collagen binds with platelets via the glycoprotein IV/ IX/V receptors, exposing procoagulant phospholipids and leading to thrombosis. ${ }^{8}$ Collagen also accelerates reparative processes and initiates wound healing through activation of inflammatory cells and tissue vascularisation. ${ }^{9}$ Collagen has also been shown to stimulate angiogenic growth factors and epithelial cell migration and proliferation, leading to re-epithelialization. ${ }^{10-12}$

Efficacy of Hemospray has been demonstrated in bleeding from peptic ulcers, cancer, and postbanding variceal ulcers. ${ }^{5,13,14}$ The first multicenter prospective nonrandomized survey analyzing the effectiveness of Hemospray in acute nonvariceal upper GI bleed from Europe (SEAL study) demonstrated successful immediate hemostasis in $85 \%$ and a rebleeding rate of $15 \%$ in nonpeptic-ulcer bleeding. ${ }^{15}$ Prasad et al who pioneered use of HS in India reported initial hemostasis in $90 \%$ of patients with peptic ulcer and rebleeding rate of $20 \%{ }^{7}$ In another study from India, initial hemostasis was 
seen in $90 \%$ of cases with rebleeding in $20 \%{ }^{16} \mathrm{~A}$ recent study from Canada on 86 applications of Hemospray could achieve immediate hemostasis in $88.4 \%$, but the rebleeding rate was high at $33.7 \%{ }^{17}$ This may be attributed to higher prevalence of Forrest $1 \mathrm{~A}$ and $1 \mathrm{~B}$ ulcers in their series. A randomized control trial compared use of Hemospray and endoscopic clip application in patients with nonvariceal UGIB, majority of whom had bleeding from peptic ulcer. ${ }^{18}$ Hemostasis was achieved in $100 \%$ patients with Hemospray as compared with $90 \%$ with hemoclip ( $p=0.487)$. However, during second-look endoscopy, 5/20 (25\%) patients required an additional hemostatic procedure.

In our study, clinical success was achieved in $84 \%$ patients with rebleeding rate of $10 \%$. The lower clinical success in our study is possibly due to use in a wide variety of causes of UGIB including difficult to treat patients with gastric malignancies. Recent guidelines from International Consensus Group recommend use of hemostatic powder like TC-325 as a temporizing therapy to stop bleeding when conventional endoscopic therapies are not available or fail, in patients with actively bleeding ulcers. ${ }^{19}$ However, monotherapy with TC-325 in patients with actively bleeding ulcers is not advisable.

Generally, all the homeostatic powders are considered safe. Transient abdominal discomfort due to rapid air insufflation and gastric distension, reported by others, was not seen by us. Allergic reaction to egg protein used for synthesis of HS, though unreported, remains a possibility with HS. ${ }^{7}$

All hemostatic powders are simple to use. Moreover, they can be used for control of bleeding from areas difficult to access with endoscopic injection, clip, or other direct methods. Availability and cost are the two major concerns, especially in our country. HS is available for about Rs 15,000/while other hemostatic powders are not available.

Our study has few limitations. This is a retrospective analysis and a single-center experience with small number of subjects.

\section{Conclusions}

HS is an effective, safe, and cost-effective tool in the endoscopic management of UGIB. Well-designed prospective multicenter studies are required to ascertain the efficacy and safety of HS to establish its role as hemostatic agent and acceptance in every endoscopy unit.

\section{Conflict of Interest}

Nil.

\section{Acknowledgments}

Our sincere thanks to Mr Pooran Singh for technical support and Ms Twinkle Singh for data management.
2 Hearnshaw SA, Logan RFA, Lowe D, Travis SPL, Murphy MF, Palmer KR. Acute upper gastrointestinal bleeding in the UK: patient characteristics, diagnoses and outcomes in the 2007 UK audit. Gut 2011;60(10):1327-1335

3 Yau AH, Ou G, Galorport C, et al. Safety and efficacy of Hemospray ${ }^{\circledR}$ in upper gastrointestinal bleeding. Can J Gastroenterol Hepatol 2014;28(2):72-76

4 Barkun AN, Moosavi S, Martel M. Topical hemostatic agents: a systematic review with particular emphasis on endoscopic application in GI bleeding. Gastrointest Endosc 2013;77(5):692-700

5 Sung JJ, Luo D, Wu JC, et al. Early clinical experience of the safety and effectiveness of Hemospray in achieving hemostasis in patients with acute peptic ulcer bleeding. Endoscopy 2011;43(4):291-295

6 Barkun A. New topical hemostatic powders in endoscopy. Gastroenterol Hepatol (N Y) 2013;9(11):744-746

7 Prasad VGM, Prasad M, Asif SM, et al. Endoscopic collagen spray- a novel method which can be used as an adjunct to conventional hemostatic techniques in peptic ulcer bleeding. J Clin Gastroenterol Hepatol 2018;2:1

8 Hess JR, Brohi K, Dutton RP, et al. The coagulopathy of trauma: a review of mechanisms. J Trauma 2008;65(4):748-754

9 Franchini M, Lippi G, Factor V. Factor V Leiden and hemophilia. Thromb Res 2010;125(2):119-123

10 Montesano R, Orci L, Vassalli P. In vitro rapid organization of endothelial cells into capillary-like networks is promoted by collagen matrices. J Cell Biol 1983;97(5 Pt 1) :1648-1652

11 Madri JA, Marx M. Matrix composition, organization and soluble factors: modulators of microvascular cell differentiation in vitro. Kidney Int 1992;41(3):560-565

12 Albini A, Adelmann-Grill BC. Collagenolytic cleavage products of collagen type I as chemoattractants for human dermal fibroblasts. Eur J Cell Biol 1985;36(1):104-107

13 Chen YI, Barkun AN. Soulellis Cetal. Use of the endoscopically applied hemostatic powder TC-325 in cancer-related upper GI hemorrhage: preliminary experience. Gastrointest Endosc 2012;75:1278-1281

14 Ibrahim M, Lemmers A, Devière J. Novel application of Hemospray to achieve hemostasis in post-variceal banding esophageal ulcers that are actively bleeding. Endoscopy 2014; 46(Suppl 1 UCTN) :E263

15 Smith LA, Stanley AJ, Bergman JJ, et al. Hemospray application in nonvariceal upper gastrointestinal bleeding: results of the Survey to Evaluate the Application of Hemospray in the Luminal Tract. J Clin Gastroenterol 2014;48(10):e89-e92

16 Sonthalia N, Jain S, Pawar V, et al. Haemoseal Spray for nonvariceal gastrointestinal bleeding: an initial experience from India. J Dig Endosc 2018;9:14-18

17 Chahal D, Lee JGH, Ali-Mohamad N, Donnellan F. High rate of re-bleeding after application of Hemospray for upper and lower gastrointestinal bleeds. Dig Liver Dis 2020;52(7):768-772

18 Baracat FI, de Moura DTH, Brunaldi VO, et al. Randomized controlled trial of hemostatic powder versus endoscopic clipping for non-variceal upper gastrointestinal bleeding. Surg Endosc 2020;34(1):317-324

19 Barkun AN, Almadi M, Kuipers EJ, et al. Management of nonvariceal upper gastrointestinal bleeding: guideline recommendations from the international consensus group. Ann Intern Med 2019;171(11):805-822

\section{References}

1 Gralnek IM, Dumonceau JM, Kuipers EJ, et al. Diagnosis and management of non-variceal upper gastrointestinal hemorrhage: European Society of Gastrointestinal Endoscopy (ESGE) Guideline. Endoscopy 2015;47:1-46 